\title{
"Can I join you?” Refugees' Emotion Regulation Experiences during Resettlement
}

\author{
Dr Marilena Antoniadou \\ Manchester Metropolitan University \\ Faculty of Business and Law \\ All Saints Campus \\ Oxford Road, Manchester, M15 6BH, UK
}

\begin{abstract}
Refugee experiences of integration is of growing importance, yet we know little about the lived emotional experiences faced by refugees themselves, the effects of their inclusion on organisational outcomes and the ways they regulate their emotions. Drawing on phenomenological interviews, this study probed the emotional experiences often refugees residing and already working in the UK. Utilising Gross's $(1998,2014)$ model of emotion regulation, we analysed how refugees used emotion regulation processes as they adapted to their new work and social environments. Findings illuminate the unfamiliarity experienced throughout their attempt to navigate to the labour market, with racism and harassment challenging their integration. However, their accounts revealed resilience and persistence to survive under adversity, which helped them develop career adaptability and contribute to their profession. This study is significant because it extends knowledge of refugee integration and highlights the ways in which refugees actively fight to survive in their new environments, ratherthan emphasising on their deficits.
\end{abstract}

Keywords: refugees, transition, inclusion; UK; resettlement; integration.

\section{Introduction}

In the culmination of international conflict in the Syrian Arab Republic, the world has witnessed the largest displacement of refugees in modern history, reaching approximately 5.5 million, since January 2018 (UNHCR, 2018a, UNHCR, 2018b). The civil war, instability and violence have made Syria the top source of refugees, with Afghanistan and South Soudan following in the list with the major sources of refugees (World Migration Report, 2018).The impact of this instability has been immense, with neighbouring countries, mainly Turkey, Jordan, Lebanon, Greece and Italy being the main destinations for refugees. Together with these countries, others have agreed to assist the resettlement of many refugees, including Germany, Canada, Australia and the UK.

Specifically, in the UK - the 6th most popular country in the EU with the largest number of asylum seekers applications (Home Office, 2018) - governmental authorities have developed policies to deal with the influx of refugees and to help their integration into society and the labour market. Nevertheless, concerns have been raised about the soaring number of refugees and asylum seekers falling into poverty in Britain, even after being granted protection in the UK (Bulman, 2018).

Research on refugees experiences (e.g. Morrice, 2013) has shown that this group of people are engaged in significant and transformative learning throughout their whole experience of relocation, which helps them to develop cultural competence and better adapt to the new sociocultural space. Refugees are recognised as people with strong psychological capital who have the potential to employ self-efficacy, hope, resilience and optimism to help them adapt to occupational transition within their destination country (Pajic,Ulceluse, Kismihók, Mol\& den Hartog, 2018). However, the experiences of refugees of being and working in the UK, together with their emotional reactions relating to socio-cultural and even professional integration in their new working environments is recognised as a relatively unexplored area within the literature (e.g. Newman et al., 2018). More importantly, despite the existence of studies that covered the vocational behavior of refugees in Turkey (Knappert, Kornau \& Figengül, 2018), in Germany (Gericke, Burmeister, Löwe, Deller \& Pundt, 2018), in Greece (Pajic et al., 2018) and in Austria (Eggenhofer-Rehart et al., 2018), the emotional experiences of refugees in the UK related to their integration in their new environments are underexplored (e.g.Willott \& Stevenson, 2013). An original contribution of this study is that it identifies processes of psychological, sociocultural and professional adaptation of refugees in the UK with particular emphasis on the factors that help or hinder this adaptation. This article starts by reviewing some key definitions in order to understand the phenomena of resettlement and integration, considers the relevance of emotion regulation theory and seeks to extend them in relation to the vulnerable group of refugees. 


\section{Refugees' resettlement and integration process}

Refugees are people who are outside their country of origin for reasons of feared persecution, conflict, generalised violence, or other circumstances that have seriously disturbed public order and, thus, require international protection (UNHCR, 2011). They are displaced people, who against their will are physically or psychologically forced to cross national boundaries and who cannot return to their home country safely. Their resettlement, involves the selection and transfer from a State in which they have sought protection to a third State that has agreed to admit them, under refugee status, giving them permanent residence status (UNHCR, 2018b).

Resettlement comprises of securing social support and finding employment (Colic-Peiskerand Tilbury, 2003). However, the conditions of resettlement are usually defined by national interests and interpreted by long bureaucracies that manage this process. According to Beiser $(1999,2006)$ resettlement involves stress deriving from unemployment, separation from family, experiences of discrimination which jeopardise mental well-being, while certain resources (e.g.ability to speak the host country language, intimate relationships, availability of a like-ethnic community) help to safeguard their mental health. While employment seems to be a central element to refugees' successful integration, only recently has this topic received more attention from organisational and vocational researchers. Integration to the labour market, securing and maintaining any type of formal employment in the host country, has been identified as a primary outcome of integration, especially for younger refugees (Gericke et al., 2018). In fact, gaining employment was early identified as a factor of improving refugees' well-being (Pernice \& Brook, 1996). Employment is highlighted as a factor that influences other areas of a refugees' life, including promoting economic independence, planning for the future, meeting members of the host society, providing opportunity to develop language skills, restoring self-esteem and encouraging self-reliance (Tomlinson \& Egan, 2002).However, entering and integrating to the labour market can be an extremely arduous process for refugees as legal status, lack of language proficiency and of formal qualifications, cultural differences, psychological/mental issues, such as traumatic stress (Li, Liddell \& Nickerson, 2016) can put further obstacles. Refugees leave their home countries having high expectations from the host nation; however, they experience underemployment and psychological contract breach (Knappert et al., 2018). As a result, refugees experience lower job satisfaction (Baran,Valcea, Porter \& Gallagher, 2018).

\section{Frameworks examining refugee resettlement}

A limited body of research represented refugees' integration to work, mostly inspired by career adaptability theories. Career adaptability is a psychosocial construct that is self-regulated and helps to inform individual differences in career trajectories. Evidence (e.g. Maggiori et al., 2013) shows that unemployed individuals have higher career adaptability than employed ones, concluding that challenging occupational circumstances trigger adaptive coping mechanisms. Therefore, refugees are more inclined to show self-control and to adjust to vocational transitions to meet resettlement goals (Campion, 2018).

Gonsalves (1992) suggested that resettlement is a stage-like process of everyday personal and social challenges accompanied by specific therapeutic needs, described in five stages through which refugees pass: early arrival, destabilisation (from 6 months to 3 years after arrival), exploration and restabilisation, return to normal life, and decomposition. Following another fixed-stage model, Marshall's (1992) transition model of refugees' employment focuses on the psychological stages that refugees go through. Following initial disorientation, and once basic needs such as housing are met, refugees are optimistic about their future prospects. However, disillusionment and depression follow when their attempts to secure employment are not fruitful. Then, a trigger, such as the provision of new information can lead to opportunities (e.g. training course), and their subsequent feelings will depend on whether the outcome is appropriate employment or not (suitable employment, underemployment or unemployment).

Other typologies include Peisker and Tilbury (2003)'s categorisation of refugee resettlement styles as "active" or "passive", and further subdivision into "achievers" and "consumers", and "endurers" and "victims" respectively. More recently, Campion (2018) suggested that refugees' arrival in a host country activates career adaptability, which influences subjective and objective resettlement success via social networks. Refugees with high levels of career adaptability will prioritise the creation and use of social networks over the acquisition of suitable jobs, which, in turn, limits objective resettlement success, such as lower status jobs, low pay, and poor language ability. In contrast, the generation and use of social networks by career adaptive refugees positively affects their physical and mental health and life satisfaction. However, these models have not had any empirical viability and remain conceptual. They tend to describe refugees' adaptability as an iterative process of overlapping phases, with no attempt to capture the complexity and unpredictability of the resettlement process, nor cases when the stages (or styles) occur out of sequence, are repeated, regulated, or even absent. 


\section{Conceptual framework}

To date, we know little about refugees' emotional behaviour in general, and how they regulate this behaviour throughout their journey. This study makes a unique contribution by drawing on a theory of adult emotional regulation (Gross, 1998, 2004) to illustrate how refugees' resettlement and integration in the labour market is not a fixed state, characterised by a sequence of emotional reactions, but is instead a process in which refugees use their experience and personal resources to integrate and survive in their new environments. Emotions facilitate adaptation, and people's emotions do not stay steady in social interactions, but flow and change (Gross, 2014). Thus, examining how refugees experience, express or regulate their emotions enriches our understanding of their adjustment to their new environments. Emotion regulation refers to individuals' attempts to influence which emotions to have, when to have them, and how these are experienced or expressed (Gross, 1998).

Gross's process model $(1998,2014)$ suggests that adults' emotions may be regulated by altering the stimulus or perceptions of the stimulus (antecedent-focused regulation), or by altering the response to the stimulus (responsefocused regulation). Antecedent-focused emotion regulation can further be categorised into four types, namely situation selection (choose to approach or avoid a certain stimulus), situation modification (change the situation to alter its emotional impact), attentional deployment (distraction or positive refocus), and reappraisal (reinterpret situations to modify their subjective meaning). Response-focused regulation is initiated once the emotion is felt and can take the form of faking unfelt emotions, suppression of felt emotions, venting and interacting with others and the use of drugs, alcohol and relaxation techniques (Gross, 1998).Engagement with antecedent-oriented emotion regulation is generally associated with good health outcomes, improved relationships and work performance (John \& Gross, 2004), whilst suppression has generally been associated with poor health and well-being outcomes (Gross \& Thompson, 2007). Personality traits and emotional abilities, motives, and contextual factors can influence the choice of emotion regulation mechanisms and their effectiveness (Gross, 2015).

Since Gross's $(1998,2014)$ model, other approaches have been identified that go beyond the five emotion regulation strategies. The control-value theory of achievement emotions (Pekrun, 2006; Pekrun\& Perry, 2014) offers another emotional regulation process relevant to this study, which postulates that emotions can be regulated by targeting the emotion itself or related attentional processes and appraisals. Regulation can, thus, be (a) emotion-oriented, by focusing attention on the emotion, such as using relaxation techniques or distracting it away with suppression; (b) appraisaloriented, by changing how the situation, task or environment is perceived; (c) competence-oriented, which involves targeting the achievement outcome by taking actions to improve competence; and (d) situation-oriented, by selecting tasks and environments to match individual goals and competencies. The control-value theory accords with Gross's $(1998,2014)$ emotion regulation theory insofar as individuals can regulate an emotion by using situation selection and modification, attentional deployment, reappraisal or suppression. However, Pekrun (2006) also postulates that people can try to regulate their emotions by changing the internal situation through competency enhancement.

In this study, Gross's process model, and its extensions, are used to explore emotion regulation strategies amongst refugees, which has not previously been attempted. It is argued that it is important to consider how emotion regulation is linked to, affects, and embraces adaptive responses to such a vulnerable group, as there is a paucity of literature about the emotion regulation processes that help refugees survive and succeed. This study addressed the following aims: (i) to increase understanding of the emotional experiences of refugees during their resettlement and integration into the UK, and (ii) to identify patterns of emotion regulation mechanisms they use in this particular context.

\section{The present study}

The research employs a qualitative methodology, strongly associated with the interpretive phenomenological paradigm, as the most relevant for a detailed description and a rich insight into the participants' experiences and the way they interpret them (Saunders, Lewis \& Thornhill, 2000). A phenomenological approach focuses on the individuals own interpretations of an experience (or a situation) and their construction of reality through narration (Benner, 1994); in this study's case, the experience of resettlement and integration in the UK labour market.

\subsection{Participants}

The study employed snowball sampling, a procedure when the researcher accesses informants through contact information that is provided by other informants (Noy, 2008). Interviews were conducted between January and November 2018. Boyd (2001) regards two to ten participants as sufficient to reach saturation and Creswell (1998) recommends long interviews with up to ten people for a phenomenological study. The data comprised of ten refugees from Syria, Iraq and Eritrea, aged between 23 to 56 years, who had received work permits in the UK and were in employment between two to ten years. The eight males and two females represent a typical gender distribution for a refugee workforce (Boyd \& Grieco, 2003). 
All were based in England, the most popular geographic region in the UK for asylum seekers (Home Office, 2018). The participants had varying professional qualifications and levels of work experience and worked in the UK on average for 5 years, with their entry dates varying from 2006 to 2016 (Table 1). When new informants did not reveal new findings and interpretations were clear, sampling stopped (Benner, 1994).

Table 1: Participants' Profile

\begin{tabular}{|c|c|c|c|c|c|c|c|c|}
\hline Pseudonym & Gender & Age & $\begin{array}{l}\text { Resettled } \\
\text { in the } \\
\text { UK }\end{array}$ & Nationality & Occupation in UK & $\begin{array}{c}\text { Previous } \\
\text { work } \\
\text { experience } \\
\text { in home } \\
\text { country }\end{array}$ & $\begin{array}{c}\text { Professional } \\
\text { Qualifications }\end{array}$ & $\begin{array}{c}\text { Years in } \\
\text { UK } \\
\text { employment }\end{array}$ \\
\hline Ashraf & $\mathrm{M}$ & 45 & 2006 & Iraq & Engineer & Engineer & University (B) & 10 \\
\hline Filippo & $\mathrm{M}$ & 38 & 2008 & Eritrea & Taxi driver & Driver & College (NC) & 7 \\
\hline Soraya & $\mathrm{F}$ & 42 & 2010 & Syria & Primary School Teacher & Teacher & University (B) & 6 \\
\hline Elias & $\mathrm{M}$ & 52 & 2011 & Afghan & Entrepreneur & Entrepreneur & University (B) & 7 \\
\hline Sami & $\mathrm{M}$ & 23 & 2016 & Syria & Grocery helper & Chef & College (NC) & 2 \\
\hline Sayid & M & 44 & 2015 & Syrian & Entrepreneur & Entrepreneur & University (B) & 2 \\
\hline Marwan & $\mathrm{M}$ & 56 & 2014 & Syria & Translator & Vet & University (B) & 2 \\
\hline Amer & $\mathrm{M}$ & 33 & 2015 & Syria & Farmer & $\begin{array}{c}\text { Football } \\
\text { player }\end{array}$ & College (NC) & 6 \\
\hline
\end{tabular}

Note: $\mathrm{B}=$ Bachelor, $\mathrm{NC}=$ Non-completed

Following the institutionally approved ethics protocol, participants were briefed about the purpose of the study, and their rights to anonymity and withdrawal at any time. Semi-structured interviews were conducted at each participant's home. In line with guidelines about coherence of emotional experience narratives (Linde, 1993), interview questions followed four broad chronological periods of the refugees' resettlement and adjustment: before coming to the UK, the early period of arrival, more recent and current experience, and future perceptions. The questions asked allowed the researcher to enter the refugees' interpreted world through their narrative. During phenomenological interviews, it is useful to ask the participants to narrate a situation during which they experienced the phenomena under study (Benner, 1994); in this study's case, to explore refugees' emotions during resettlement and integration in the UK labour market. The interview schedule focused on questions around the participants' general background, career history, resettlement and transition to England. Examples of questions used in the interviews included: 'Imagine that I am an author, who comes to you asking to describe what it is like being a refugee who has now resettled in the UK workplace. Can you describe the main emotions that are part of the being a refugee?', 'How did you react?', 'Can you describe what helped you find a job in England?' Interviews lasted from two to two and a half hours and were all audio-recorded and transcribed verbatim.

\subsection{Analysis}

Data were analysed using thematic analysis focusing on interviewees' experiences and what they spontaneously perceived to be important in their integration. The analysis was carried out in an ongoing iterative process in which we alternated between what the refugees perceived of their integration and adaptability and how they responded to any challenges.

Phase 1 involved acquiring a general grasp of the first interviews by reading each transcript several times, with unclear pieces being tagged as lines of inquiry for further interviews. Some lines of inquiry involved the level of support participants received, as contrasting experiences were found amongst participants. Phase 2 involved identification of important themes, such as obstacles affecting the participants, with salient excerpts (exemplars) for each early participant's story. As researcher's interpretations began to emerge, summaries of meaningful common patterns and concerns amongst informants were created. For example, it soon became evident that turning to other refugees for social and moral support was common in many stories. Once this exemplar was identified, seeking beneficial interactions, on a broader level, began to be recognised in subsequent stories. We then continued to move back and forth between the transcripts and portions of the interpretation and carefully developed a range of exemplars to allow the reader to recognise the distinctions we made and to illustrate the patterns of emotion regulation strategies.

In Phase 3, the written interpretive summary showed connections between meanings found within stories and constitutive patterns. The shared participant meanings, captured in the written interpretive summaries, were then compared with various findings of refugee experiences, as outlined in the introduction. Once a pattern of meaningful 
themes was identified, extracts from the interviews were used to demonstrate similarity or contrast. In Phase 4, final interviews addressed pending lines of inquiry, and in-depth interpretations of exemplars and interpretive summaries were developed. Phase 5 continued the final interpretation to validate interpretations and themes and determine whether concerns had been answered and whether interpretation broadened options for policy interventions and research.

\section{Findings}

Following specific guidelines for phenomenological interview analysis, as indicated above, the findings represent the key themes determined from the clusters of relevant meaning. Firstly, the participants' perceptions are reported about their emotions during the four chronological periods (Linde, 1993) that shaped the data collection. Then, the findings are reinterpreted using Gross's $(1998,2014)$ model of emotional regulation, expanded to include competence-oriented regulation (Pekrun\& Perry, 2014). Figure 1 provides a summary of the findings.

\subsection{Before coming to the UK: a period of torture}

Before coming to work in the UK, participants felt fear, insecurity, stress and even frustration with the political turbulence in their home countries. All participants mentioned they had experienced torture and significant challenges that damaged them emotional and sometimes physically. This torture prompted them to flee. Ashraf came to the UK in 2006 from Iraq. His story was typical of many of the refugees that participated in the study:

I went to pick up my two kids one day from school, when a bomb landed in front of my eyes close to the school. I saw nothing but blood. I could only hear screaming and thank God that these screams also came from my kids. My kids have lost their childhood because of the war. I was scared, stressed and angry.

Other participants experienced extremely traumatic events; they had lost family members (sometimes in one day) and their homes. Migrating, many said, 'was our only option'. Many stories were about torture, loss of property, malnutrition, physical assault and loss of livelihood. As Ashraf said 'the whole world wants you dead, and you try to survive from bombs, attacks and hatred'. Soraya was struggling to explain the period before she came to the UK:

It's more than being scared. I was horrified, shocked. I can only remember severe things, all unpleasant memories for years...It's a gamble. You either stay and risk your life every day, or leave for a better future. Would you stay? I doubt it.

Each participant highlighted certain stages of their migration journey. The migration process lasted days or years for many. Walking for days, suffering from starvation and hostility, being robbed and frequently being separated from family members. Many shared experiences of being cheated by people who offered to help them and being betrayed by their own people. Experiencing misanthropy from others disheartened participants, as Elias said 'fear and anger dominated us, as we couldn't trust anyone'. This lack of trust was an obstacle throughout the whole migration journey.

\subsection{The early period of arrival: starting a new life}

During their first few days in the UK, participants were put into accommodation or stayed in detention centres, since many refugees arrived with few financial resources. The process to gain refugee status lasted for months, during when they were not allowed to work. Their stories covering this period were mostly about their camp experiences and voluntary and work engagements. Participants described this period as a period of agony, distress, but with moments of optimism, especially when they heard that some of their friends were granted refugee status. Social isolation, poverty, unemployment, overcrowded and unsafe housing,and a chronic sense of uncertainty regarding their future were the major threats.

Despite being unfamiliar with the UK culture, many participants claimed that the government, NGOs and charities treated them fairly. The only hostility they faced was coming from local citizens, who saw them as 'intruders'. Ashraf's story was typical of the societal rejection:

I knew I looked different, darker in skin and exhausted from starvation. I used to go to the local convenience store and asked "Can I join you?" but the owners were hostile. One of them called the policy to check if I was illegal. I had not committed any crime, yet I was treated as a criminal.

Finding a job was a key priority. They were determined to work and they wanted to contribute to the country with their experience and qualifications, in dignity, freedom and security. Staying in refugee centres was not easy. Whilst the majority of participants were competent in English language, they were keen to undertake courses to enhance their employability and even do volunteering work.

However, they faced several restrictions on attending these courses which asylum-seekers could not undertake, while they were waiting from the Home Office to process their applications. Volunteering was a solution for many, who hoped to receive some money as a reward for their hard work and willingness to help. In Manchester, two of the participants, Sayid and Sami, found a sense of community by volunteering at a local retirement home. Adnan, an 
experienced journalist, was given the opportunity to contribute to a local newspaper byreporting on the experiences of refugees once they arrive in the UK, showing the refugee journey from the perspective of those experiencing it. Amer, a football player in Syria, expressed his enthusiasm and how 'thrilled and grateful' he was when a family-run local farm encouraged them to visit the farm every day to learn skills such as painting, weaving, ceramics, cooking and agriculture.

Despite having previous educational qualifications and employment experience, some participants could not get direct access to employment. There was unwillingness from people to give them jobs, which Elias described as 'undermining'. In some cases, participants mentioned the frustration of not having enough help with the many administrative and legal procedures to lower the personal and legal barriers they faced before they could enter the job market. However, none of them claimed to be demotivated to continue trying. They were all keen to "make a full contribution to society, just like I did in Iraq', as Ashraf said.

\subsection{Recent and current experience: being able to rewind}

For the participants, being on the move meant that they were exposed to a range of events, relationships and work experiences, which they highlighted as an influential part of their current professional experiences. These refugees were settled, yet they were still constantly shaping and reshaping their career plans. Encounters with other displaced refugees and workers of international humanitarian organisations were factors that enhanced and eased the participants' transitions. They storied that they are now settled and make career plans, educational decisions as some have sent their children to Universities and highlighted eagerly and repeatedly how they are not afraid anymore. For instance, Amer who described his positive experience with a local farm, proudly said that he works for the owners full time now and 'it's the most rewarding job I could ever had - I never thought strawberry picking and making home-made jams would be so fun!' Amer and his mother are now making plans of starting their own project of making Syrian jams and Makdoos to enrich the production of the farm.

Entrepreneurship was a popular form of employment for four of the participants. Sayid said that, given his expertise, he decided to start his own business, similar to the one he had left behind in Syria and that his business was going very well making him feel 'worthy'. Similarly, Elias created his own trading business and was proud that he opened the door for employment opportunities for other refugees. Filippo stressed how international humanitarian organisations encouraged him to become a self-efficient worker:

I am now a taxi driver and I know Manchester better than the locals. I see the city as home now. I know I'm not local and will never be, my accent my looks tell you that. But I'm proud and happy. I became from a shy person to the most talkative driver, getting the best feedback from passengers. I interact with people, I listen to their stories and they hear mine. I'mpleased to be able to raise some awareness of what's happening in my country and to contribute here.

Contrary to Filippo, Marwan was unemployed for two years until he found a job as a translator, despite being a vet in Syria:

The most important thing now is to just work, not the type of job. It's the principle of working, of being able to contribute to the country and support your family. It's humiliating because people think you're just happy to have money from the government and not work. But it's not!

People like Marwan were aware of the significant barriers that prevented them from practicing their discipline and were disillusioned by their negative experiences of finding work in their chosen field. Yet, they highlighted how 'relaxed' and 'relieved' they were, once they secured employment. England is now 'home' for these refugees, although their thoughts are with their other relatives who they hardly speak now.

Naser even recognised that working as a teacher for the past three years fills him with energy as 'the atmosphere at work is fulfilling and I now achieve my ambition which is working as a teacher in the UK'.

\subsection{Future perceptions: home is where you make it}

Refugees storied their anticipations about future career plans. They all agreed that the UK is the place they were reborn. Recognising that they may never be able to return home, Sayid appeared realistic that:

Home is always where you make it. And for me and my family we are home now. You know, people, like us, have a strong belief in God, so we forget those torturing. The images and memories disappear in time.But the heartbreak stays, sometimes forever.

Others said that they felt 'betrayed' by their own country and that the UK is their only choice of a safe life. They confirmed that the UK is full of opportunities and despite patronising experiences they had (and are still having), they talked about their future optimistically, with pride re-emerging, marked by their realisation of what they had achieved despite challenges. Adnan said that working as a journalist is 'fulfilling' and shared the story when his colleagues did a 
fundraising to help him and his family. He said that this was the 'most precious gift anyone has done for us'.Soraya explained how her traumatic experiences from war in Syria helped her to share her story with her students who are now exposed to cross-cultural experiences. She is now engaged in her job and realised that 'whilst I still experience moments of emotional pain, I feel like home', mentioning having even a sense of belonging. As Ashraf concluded, 'I'mheartened and proud to be able to survive and reborn from ashes and live in a beautiful country', highlighting his motivation to contribute and be self-efficient in his job as a car engineer.

\subsection{Emotion regulation strategies}

Participants' resettlement and successful integration was characterised by engaging in various emotion regulation strategies. Antecedent-focused emotion regulation was demonstrated by their choice to resettle, an example of situation selection. In choosing to move to the UK, they took initiative to remove themselves from unsafe and traumatic situations. Their self-determination to survive and succeed in a new country helped these refugees to restart their lives, and to feel safe again. A commonly used strategy of situation selection was seeking interactions with other displaced people. All participants talked about the role of a range of supportive, guiding, encouraging and inspirational relationships with displaced people, colleagues and people from humanitarian organisations, as this helped them gain a more benign perspective. They all described the empowering effect of help from other refugees or from family and friends, both during job search and at jobs. Refugees also exercised agency by taking action to modify situations and rise to challenges (situation modification). When Soraya faced a patronising event, shetried to modify the situation by explaining her state:

During my job interview, they challenged me for not having experience of working under pressure. I took a few breaths and said: "I'll tell you about pressure. Pressure is watching bombs falling outside your house and lying to your 3-year old that they are simply filming a horror movie. Pressure is finding dead bodies in the bin and go back home and breastfeed. Pressure is walking from country to country, with your child on your shoulders, but always tell a bedtime story to your kids, so that they won't feel scared. Do you seriously think I cannot manage pressure?"

In attempts to alter other people's perceptions about how much they were worth, other participants shared stories of how much they insisted to convince people to give them a job. Many examples included proactive job seeking and deliberate efforts to convince local companies of their suitability and likability. Participants also focused on specific elements of situations (focusing attention), such as engaging in volunteering work to help them forget the past. Other examples of redirecting their thoughts to more pleasant elements included helping other refugees that arrived more recently that they found rewarding, or planning short walks around their centre to unwind from stressful situations and meet the city.

Their determination to succeed in the UK, especially in their jobs, fuelled them to reappraise situations and to establish new perceptions. Ashraf, who described his struggle to speak to local people after facing multiple harassments, he reappraised his thinking of how to approach people:

You can't just disappear and go home. There is no other option but stay and fight. Once I realised this, it helped me move forward in an optimistic way...So rather than feeling depressed about hostile people and the way they treated me, I decided to approach them and tell my story. Refugees are fighters, but people don' trealise this. I could understand why people are hostile. I was the intruder not them. I went to the local shops and showed them what I can do. I'm a computer engineer, so I helped them voluntarily with their keyboards, routers, and printers. In terms of responsefocused regulation strategies, suppression was used to hide their reactions in negatively-appraised situations. When Soraya and Ayawere faced with discriminatory comments at work, they did not show any frustration, as they did not want to generate any conflict with the locals.

For months, Soraya was facing criticism from her students' parents but she chose to mask how insulted she felt. She admitted being worried of 'social disapproval' from the parents if she chose to defend herself. However, while initially employing suppression, she later demonstrated reappraisal, which had different consequences of how she thought and felt:

I didn't speak at first and suffered silently. Then, I realised that if I had my child being taught by a stranger, I might be worried too. So, I decided to make them empathise with me. I showed them pictures of my students in Syria and shared how difficult it actually is for me to be away from home, without my will. With time they realised that their children are not in danger with me.

Participants also chose to regulate their emotions by enhancing their competencies. This type of competence-oriented regulation was mentioned by all participants, who referred to development programmes that help refugees meet their basic needs. These series of training sessions helped them boost their confidence and address mental health issues. Elias said: 
There were some people from universities coming to talk to us about creating new social networks through communal spaces and activities, to help us reduce isolation and increase social support. These training courses were exclusive for us and massively helped me.

Sami's training was specifically for young refugees and asylum seekers, organised by an NGO that operates across Europe. As a young refugee, he argued that they created an online training tool for them, with innovative face to face and virtual training, whilst also helped them generate peer-to-peer networks to share and learn about working with refugees.

\section{Discussion}

The findings support critiques of early descriptions of refugee resettlement(e.g. Marshall, 1992) as iterative or as having fixed emotional reactions over time, either "active" or "passive" (Peisker\& Tilbury, 2003), suggesting that those arguments are over generalised. Participants experienced resettlement as more like a roller coaster of emotions occurring (and re-occurring) throughout various periods, dependent upon their chosen emotion regulation processes. The study, therefore, argues that refugees cannot be either in a passive or in an active state, during which they simply take in what is happening to them and suffer anxiety, but actively work to adjust to their new environment. Instead of a fixed, iterative process of overlapping phases of resettlement and integration, this study considered the particular experiences encountered over time (e.g. dealing with displacement, adversity, hostility, change of status, finding new jobs independently from their qualifications, creating new relationships, societal rejection) and the relationship between opportunities in the host culture and the refugees' emotional regulation processes. This approach emphasises the ways in which particular emotions (e.g. fear, frustration, optimism, pride) were experienced iteratively across the periods of displacement and the agency that the refugees exercised from initial contact to eventual integration.

As other studies identified (e.g. Eggenhofer-Rehart et al., 2018;Colic-Peisker, 2006), there is no fixed or common pathway for refugees; the participants had veered from fear to optimism and back again many times in their pursuit of resettlement, integration and search for employment. It was also confirmed that refugees are individuals characterised by resilience, adaptability and determination to succeed (Campion, 2018).Participants, having gone through adversity and life-changing events, they felt integrated in the UK society, and they stated being willing to contribute and make significant changes in their jobs. The fact that the vast majority of the participants were experienced professionals upon arrival may have contributed to their success. Yet, in some cases, incidents of societal fear and rejection of refugees occurred, mirroring previous arguments of patronising behaviour (e.g. Colic-Peisker, 2006).

This study illustrated how participants actively managed their emotions through various psychological processes that helped them to improve their lives during resettlement.To illustrate these mechanisms, an integrative framework of emotion regulation is proposed (Figure 1), which builds on Gross's model of emotion regulation (1998, 2014). Our findings go beyond Gross's $(1998,2014)$ five emotion regulation strategies to include competence-oriented regulation (Pekrun 2006; Pekrun\& Perry 2014), a form of regulation that involves action to develop skills and abilities to learn, improve and succeed in their new environments. Competence training was supported by institutional initiatives that participants used to increase perceived control, self-confidence and achievement and changed their emotions, facilitating their successful adjustment. In alignment with previous findings (e.g. Morrice, 2013), refugees seem to seek and engage in learning activities during their relocation, as a crucial factor that helps them to better adapt to the new environment. 
Figure 1: Emotion regulation strategies during refugee resettlement based on Gross (1998, 2014), Pekrun (2006)

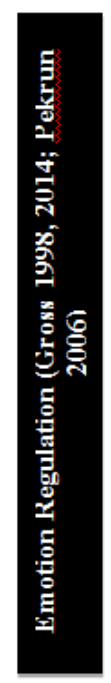

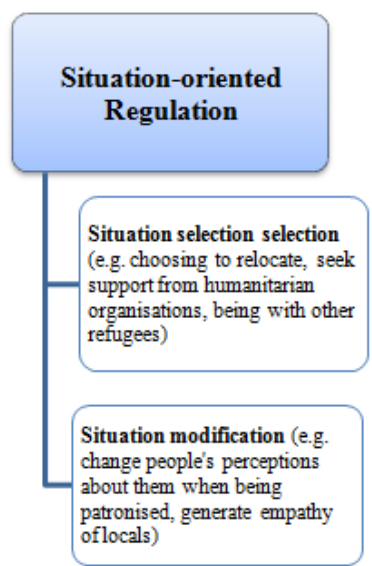

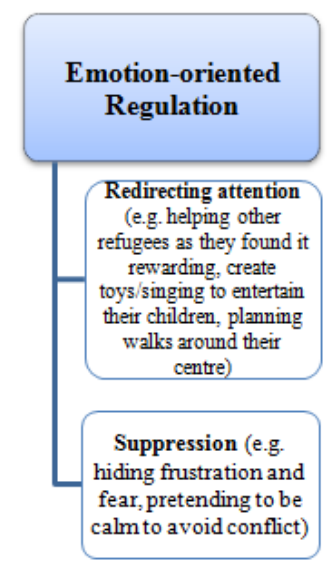

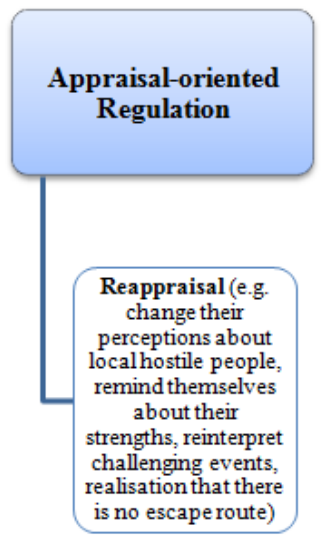
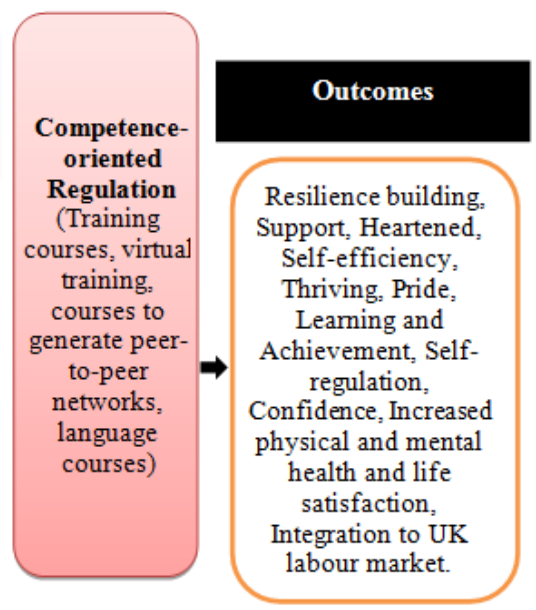

Experiences: adversity, witnessing war/dictatorship, loss of beloved ones, misanthropy, physical injuries and

exhaustion, status changes, trauma, homelessness, harassment, societal rejection, non-recognition of qualifications. Personal Resources: resilience, tenacity, high motivation/determination to succeed, hope, optimism, persistence, faith/religion

Antecedent-focused strategies, such as situation selection (e.g. seek help from humanitarian organisations), situation modification (e.g. attempt to change other people's perceptions), and redirecting attention (e.g. singing/creating toys for their children) were mentioned as effective mechanisms to help them cope with adversity. Consistent with previous research on refugees' resettlement (e.g. Gericke et al., 2018; Baran et al., 2018), being amongst people that made them feel good, especially other refugees, volunteers and NGO's workers, was a powerful regulation strategy (situation selection), as it helped the participants regain their confidence. Reappraisal was a commonly reported strategy and led to long-term benefits by enabling to recover from setbacks (John \& Gross, 2004).

Participants' choice to engage in emotional regulation seemed to be rooted in their persistence and conviction that they were in the UK to escape death and to succeed again. This tendency to actively fight the challenges strengthens arguments that refugees are highly self-sufficient, tenacious, independent, and better adjusted to cross-cultural transition because of prior difficult situations (situation selection in the first place) (e.g. Baran et al., 2018). Their tenacity and self-drive seemed to underlie their efforts to change their thoughts and behaviours to survive the challenges, which aligns with Tomlinson and Egan's (2002) idea of 'empowerment' and self-help as refugees present themselves as active agents. On the other hand, suppression, a variant of emotion-oriented regulation (Pekrun\& Perry 2014) was used in stressful events, particularly when they were concerned about escalating conflict with other people.

It is possible that because most interviewees had an established career trajectory before resettling to the UK they were more capable of exercising agency and being persistent and disciplined, making resettlement a smoother process (Willott\& Stevenson, 2013). Therefore, by choosing to interview those who had survived at least two years (the average length of resettlement in the UK among the sample was 6,1 years) the study highlighted the strategies of those who were successful. It is also possible that these refugees' strong motives to succeed, their emotion-regulation selfefficacy, and emotion regulation aptitudes have influenced emotion regulation mechanisms, as discussed by Gross (1998, 2014).

\section{Implications}

This study has important practical implications. The experience of some participants suggested examples of good practices in supporting refugees, namely addressing challenges associated with the resettlement journey, transition to the host country, providing competence-training and sharing with organisational members the benefits that refugees bring to a society, by raising awareness of such findings. Considering that emotion regulation interventions were effective to the participants of this study, there are ways of fostering the psychological wellbeing among refugees. Essentially, interventions in the workplace by reducing toxic stressors (e.g. hostile colleagues and managers) and fostering resilience and recovery from war-related violence and loss is key. 
Such interventions can take the form of training refugees to address and incorporate mental health issues, helping refugees create new social networks through communal spaces and activities, in order to reduce isolation and increase social support. Emotion regulation interventions designed by organisations to teach healthier patterns of emotion regulation could be offered, which have been suggested as effective for minorities working in other contexts (Gross, 2014). Further recommendations for organisations to foster inclusion may include: a mandatory induction programme that embeds aspects of the UK culture and working life; explicit provision of counselling facilities on arrival; the establishment of support groups for refugees and their families. It is further suggested that refugees who have survived the resettlement journey, to act as mentors to newly-arrived asylum seekers, especially when considering how often this was reported from the study's findings.

There is a moral imperative to provide needed services to the people to whom we open our doors. It also makes good sense to support successful resettlement. An early investment in their future helps to ensure that people admitted as refugees will become contributing members of their adopted societies and organisations (Beiser, 1999).

\section{References}

Baran, B.E., Valcea, S., Porter, T.H., \& Gallagher, V.C. (2018). Survival, expectations, and employment: An inquiry of refugees and immigrants to the United States. Journal of Vocational Behavior, 105, 102-115.

Beiser, M. (1999). Strangers at the gate: The 'boat people's' first ten years in Canada. Toronto: University of Toronto Press.

Beiser, M. (2006). Longitudinal research to promote effective refugee resettlement. Transcultural Psychiatry, 43(1), 5671.

Benner, P. (1994). Interpretive phenomenology: Embodiment, caring, and ethics in health and illness. Thousand Oaks, CA: Sage.

Boyd, C. O. (2001). Phenomenology the method. In P.L. Munhall (Ed.), Nursing research: A qualitative perspective, (3rd edition).Sudbury, MA: Jones and Bartlett. (93-122)

Boyd, M. \&Grieco, E. (2003). Women and migration: incorporating gender into international migration theory. Migration information source, 1(35), 28.

Colic-Peisker, V. \& Tilbury, F. (2006). Employment niches for recent refugees: Segmented labour market in twentyfirst century Australia. Journal of refugee studies, 19(2), 203-229.

Creswell, J. W. (1998). Qualitative inquiry and research design: Choosing among five traditions. Thousand Oaks, CA: Sage.

Eggenhofer-Rehart, P. M., Latzke, M., Pernkopf, K., Zellhofer, D., Mayrhofer, W. \&Steyrer, J. (2018). Refugees' career capital welcome? Afghan and Syrian refugee job seekers in Austria. Journal of Vocational Behavior, 105, 31-45.

Gericke, D., Burmeister, A., Löwe, J., Deller, J. \&Pundt, L. 2018. How do refugees use their social capital for successful labor market integration? An exploratory analysis in Germany. Journal of Vocational Behavior, $105,46-61$.

Gonsalves, C. J. (1992). Psychological stages of the refugee process: A model for therapeutic interventions. Professional Psychology: Research and Practice, 23(5),382.

Gross, J.J. (1998). Antecedent-and response-focused emotion regulation: divergent consequences for experience, expression, and physiology. Journal of personality and social psychology, 74(1),224-237.

Gross, J.J. (2014). Emotion regulation: Conceptual and empirical foundations. In J.J. Gross (Ed.), Handbook of emotion regulation, 2nd ed.: 3-20. NY: Guilford.

Gross, J.J. (2015). Emotion regulation: Current status and future prospects. Psychological Inquiry, 26(1),1-26.

Gross, J. J. \& Thompson, R. A. (2007). Emotion Regulation: Conceptual Foundations. In J. J. Gross (Ed.), Handbook of emotion regulation: 3-24. New York: Guilford Press.

Home Office 2018. How many people do we grant asylum or protection to?, Available online: https://www.gov.uk/government/publications/immigration-statistics-year-ending-june-2018/how-many-peopledo-we-grant-asylum-or-protection-to, Published 23 August 2018.

Knappert, L., Kornau, A. \&Figengül, M. (2018). Refugees' exclusion at work and the intersection with gender: Insights from the Turkish-Syrian border. Journal of Vocational Behavior, 105, 62-82.

Li, S. S., Liddell, B. J., \& Nickerson, A. (2016). The relationship between post-migration stress and psychological disorders in refugees and asylum seekers. Current psychiatry reports, 18(9): 82.

Linde, C. (1993). Life stories: The creation of coherence. New York: Oxford University Press.

Maggiori, C., Johnston, C. S., Krings, F., Massoudi, K., \&Rossier, J. (2013). The role of career adaptability and work conditions on general and professional well-being. Journal of Vocational Behavior, 83(3), 437-449. 
Marshall, T. (1992). Career guidance with refugees, London. British Refugee Council.

Morrice, L. (2011). Being a refugee: Learning and identity. A longitudinal study of refugees in the UK. Trentham Books.

Newman, A., Bimrose, J., Nielsen, I.\&Zacher, H. (2018). Vocational Behavior of Refugees: How do Refugees Seek Employment, Overcome Work-related Challenges, and Navigate Their Careers?.Journal of Vocational Behaviour, 105, 1-5.

Noy, C. (2008). Sampling knowledge: The hermeneutics of snowball sampling in qualitative research. International Journal of social research methodology, 11(4), 327-344.

Pajic, S., Ulceluse, M., Kismihók, G., Mol, S.T. \& den Hartog, D.N. (2018). Antecedents of job search self-efficacy of Syrian refugees in Greece and the Netherlands. Journal of vocational behavior, 105,159-172.

Peisker, V. C. \& Tilbury, F. (2003). "Active" and "passive" resettlement: The influence of support services and refugees' own resources on resettlement style. International Migration, 41(5), 61-91.

Pekrun, R. (2006). The control-value theory of achievement emotions: Assumptions, corollaries, and implications for educational research and practice. Educational Psychology Review, 18(4),315-341.

Pekrun, R. \& R. Perry. (2014). Control-Value Theory of Achievement Emotions. In R. Pekrun, \& L. LinnenbrinkGarcia (Eds) International handbook of emotion, in education, 120-141. New York: Routledge.

Tomlinson, F. \& Egan, S. (2002). From marginalization to (dis) empowerment: organizing training and employment services for refugees. Human Relations, 55(8), 1019-1043.

United Nations High Commissioner for Refugees. (2011). Conventional and protocol relating to the status of refugees. Retrieved from http://www.unhcr.org/en-us/protection/basic/3b66c2aa10/convention-protocol-relating-statusrefugees.html.

United Nations High Commissioner for Refugees. (2018a). Asylum in the UK, Available online: http://www.unhcr.org/uk/asylum-in-the-uk.html, Accessed 10th November 2018.

United Nations High Commissioner for Refugees. (2018b). Information on UNHCR Resettlement, Available: https://www.unhcr.org/information-on-unhcr-resettlement.html, Accessed 29 November 2018.

Willott, J., \& Stevenson, J. (2013). Attitudes to employment of professionally qualified refugees in the United Kingdom. International Migration, 51(5), 120-132. 